ENTREVISTA 


\section{Del poder de la palabra al sueño del Paraíso \\ (Entrevista a Patrick Charaudeau)}

\section{Por René Arrieta Pérez ${ }^{1}$}

Patrick Charaudeau es lingüista, especialista en Análisis del Discurso, profesor de la Universidad de ParísNorte (París XIII). Autor del Diccionario de análisis del discurso, Discurso de la información, Discurso en los medios, Lenguaje y discurso, entre otros libros. Ha publicado, así mismo, innume-

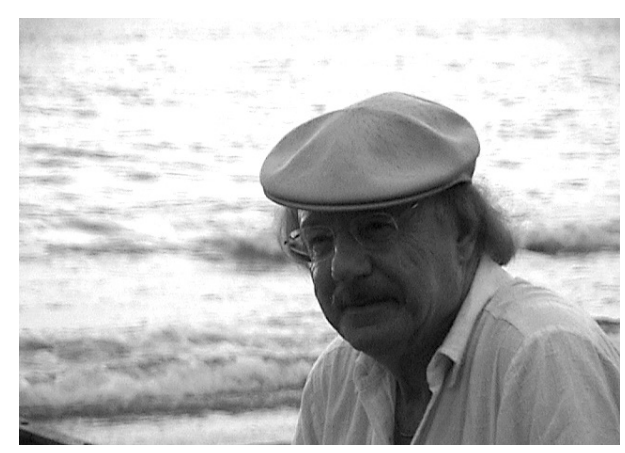

Foto: Lil Martha Arrieta rables artículos. Su preocupación ha sido el poder y el discurso del poder, el contrapoder, los medios y las relaciones de poder, las relaciones de fuerza, los juegos de seducción y de persuasión, todos dentro de los juegos de regulación social, que obligan al individuo a usar estrategias para imponerse en la relación. Asimismo, Charaudeau se ha ocupado de la interpretación de fenómenos como el humor y la emoción. Con Charaudeau tuvimos el espacio y la oportunidad para tratar, también, en esta entrevista, sobre el origen y el carácter de los nombres, la palabra, la poesía, el lenguaje del paraíso, el humor y otros temas.

-Los nombres siempre significan algo o hablan del origen, del lugar y de otros significados. En algunas culturas, incluso, se oficia una consagración a través del nombre. El suyo qué significa.

Bueno, es verdad, los nombres, lo que se llama nombres propios, los apellidos, ¿no? Vienen de una tradición, por lo menos en Europa; porque me he fijado que acá, en los países de inmigración, después de la primera época, la gente tenía los nombres que les habían dado

${ }^{1}$ Escritor y periodista colombiano. Profesional en Lingüística y Literatura de la Universidad de Cartagena. Doctorando en Literatura Española e Hispanoamericana de la Universidad de Salamanca. e-mail: arrietarene@hotmail.com 
sus papás, sus familiares allá en Europa. Después de eso hubo una gran libertad (me doy cuenta cuando veo la lista de los alumnos matriculados, nombres para mí muy raros), y demuestra que hay una cierta libertad en la elección de los nombres, siempre que no se encuentre uno en un país, en una cultura en la cual se especifica, y hasta hay una lista previa. Le voy a contar una anécdota referente a mi propia vida. Cuando nací mi papá fue a - ¿aquí cómo se dice?, ¿la alcaldía?- la alcaldía, bueno, para declararme (registrarme) y quería llamarme Patrick. Pero da la casualidad de que en aquella época el nombre de Patrick no existía. Existía, por supuesto, pero no estaba en la lista de los ayuntamientos en Francia. Entonces el señor que estaba ahí dice: "Patrick. No, no es posible, porque no existe en nuestra lista. Ahora, si quiere le propongo Patricio". A mi papá el Patricio lo encontró horrible, y dijo: "Ni hablar. Patrick o nada". El otro dijo: "Nada”.

Mi papá se fue y no me declaró durante una semana, o quince días, hasta que mi mamá le preguntó si me había declarado, y él se enojó: "No, no quieren Patrick". Volvió al ayuntamiento y tuvo que declararme Patricio. Desde entonces se me plantean unos problemas terribles, porque toda la gente me llama Patrick, siempre me llamo Patrick, y en algunos de mis documentos aparece Patrick, pero en la data de nacimiento aparece Patricio; en el pasaporte aparece Patricio, pero en la cédula aparece Patrick. Tengo una serie de problemas, que no sé si existo como Patrick o como Patricio. En cuanto al apellido, Charaudeau tiene su historia también, porque "Charaud", etimológicamente, viene de "carro", y antiguamente era el carro donde se ponía la uva para llevarla al lagar y hacer vino. Resulta que en mis antepasados había un viticultor, pero debía ser pobre, porque le pusieron el sufijo "eau" que quiere decir "pequeño", lo que indica que tenía un carro pequeño y que hacía vino en poca cantidad. Después se pierde la memoria de eso, pero efectivamente, como usted dice en la pregunta, los nombres y apellidos son portadores de algo, de una región, de unos comportamientos, de unas prácticas y de una cultura, incluso.

\section{-También provienen del santoral.}

Y del santoral también, muchas veces. A mí me llama la atención que casi todas las mujeres tienen en su nombre María. Viene al principio, viene al medio, viene al final, pero siempre hay una María. Y bueno, es eso, la característica de los nombres cuya significación es marcar una filiación. En realidad, es todo un juego entre mantener una filiación o romper con la filiación. Según la vida de la gente, se escoge romper o marcar esa filiación. No sé si 
aquí en Colombia existe la tradición de que al hijo mayor se le da el nombre del padre y a la hija mayor el de la madre, ¿no? En España, sí, y así se remarca la filiación.

\section{-Aunque Patricio de Patriciado, si vamos a Patricio.}

Claro. Y Patrick, que es otra cosa, es de origen irlandés. Era un santo, un combatiente, parece ser. ¡Guerrerooo! Y Patricio de patriciado, de patriarcal, de toda esa filiación etimológica.

-Cuando habla de conocimiento e interdisciplinariedad, referencia a Pierre Bourdieu en lo que respecta al juego institucional: todo campo de conocimiento se convierte en campo de poder. ¿Cómo podríamos explicarlo?

Es una hipótesis sociológica o un postulado, si se quiere, y la característica del postulado es que no se define, se impone. En Bourdieu está la idea de que todas las relaciones de los individuos en una sociedad son relaciones de fuerza, pero no forzosamente de guerra, y si lo son, es una guerra y una lucha simbólica, ya que cada uno, para constituir su propia existencia e identidad, lo hace en diferencia con el otro, a veces en contra del otro. Pues en la medida en que el otro fuera completamente idéntico a mí, no me podría dar cuenta de mis propias características. Al observar que es diferente, yo me pregunto cuáles son las diferencias y los puntos comunes. A partir de la percepción de esas diferencias es que tomo conciencia de mi propia existencia y de mi propia identidad. A nivel colectivo pasa lo mismo: un grupo social se define y toma conciencia de su identidad al enfrentarse con otro grupo social diferente. Esa es la base del razonamiento, y con él surge otro movimiento: Si el otro es diferente es que a lo mejor es mejor que yo. Entra en una dinámica que hace que ese otro piense y diga: "Voy a intentar apoderarme de él para que entre en mi propio universo de discurso". El otro, sin embargo, también quiere hacer lo simétrico.

De este juego de tira y afloja nace una serie de relaciones de fuerza. Bourdieu no inventó el concepto, sino que lo formalizó, porque ya los griegos lo decían: la toma de conciencia de uno depende de la mirada del otro. 0 sea, lo que me constituye es la mirada del otro, en su diferencia, precisamente. Hay que aceptarlo. Se dice: el mundo es una guerra constante. Sí, es una guerra constante, porque si no lo fuera, sería siempre una guerra con armas. Así es una guerra simbólica. Es una paradoja: necesito al otro para constituirme, pero otro diferente, y al mismo tiempo, quiero que ese otro sea idéntico. Es este juego el que hace que constantemente haya relaciones de fuerza entre los 
individuos, ya sea interpersonal o colectiva -desgraciadamente, a veces se llega hasta las guerras-. Por ejemplo, fíjese en la vida de una pareja. Cada uno quiere seguir existiendo, y siempre está en esas relaciones, a veces hay conflictos, pero hay que pensar que esos conflictos son la señal de que cada uno quiere existir en la relación de pareja. Siempre tenemos esa idealidad, que una pareja es la fusión total, es el amor total. Hay momentos así, pero si cada uno quiere existir, tiene que marcar su diferencia con respecto al otro.

-En algún momento usted ha escrito que el "discurso de comentario", que se origina a partir de la mediación del discurso en los mass media, y se opone al discurso elaborado, académico, también se genera dentro de un contexto de información y conocimiento. ¿Cuáles son las especificidades del "discurso de comentario"?

En mi teoría planteo la hipótesis de que la comunicación social se hace a través de unos "contratos". Contrato es la manera como en una situación de comunicación esa situación da unas pautas, unas obligaciones que hacen que si estoy en una situación de entrevista no estoy en una situación amistosa con otros, no estoy en una situación de conferencia, no en la situación de leer un texto o de escribir una carta. Toda situación se puede considerar una especie de contrato que nos liga al que habla, al que escribe, al que lee o al que escucha, para poder intentar establecer una intercomprensión. Si se parte de esa hipótesis, se puede decir que el mundo científico tiene su propio contrato, y ese contrato exige una cierta manera de hablar, de escribir. Tiene conceptos, tiene una metodología, usa términos comunes, pero en realidad los términos que se usan en una ciencia, en una disciplina, cuentan con un sentido específico que el vulgo no entiende, porque es un sentido específico, una especie de jerga. En este caso se habla de léxico y de lenguaje técnico.

Si uno está en un coloquio entre científicos, ese contrato hace que manejen el mismo tipo de lenguaje. Así se pueden entender, discutir, polemizar, si quieren, y esto forma lo que yo llamo una controversia científica. El contrato científico con ese lenguaje técnico tiene como finalidad establecerverdades, demostrar verdades y probar verdades. Ahora, los medios de comunicación -prensa, radio, televisióntienen su propio contrato, que no es el mismo. En el campo de los medios el contrato es uno de información, no de demostración de la verdad. Se presupone que la verdad ya se ha dicho en alguna parte; por lo tanto, el papel de los medios de comunicación es hacer llegar al público, que no es especialista, resultados científicos o elementos de controversia. Lo tiene que presentar, no obstante, de una manera 
que el gran público pueda entender. El papel de los medios es una actividad de traducción y adaptación. Por consiguiente, es normal que usen el vocabulario de los científicos, pero vulgarizado. A veces eso crea conflictos, porque los científicos dicen: "Ah, no es así, porque ese concepto no es el mismo".

\section{-¿El papel de los medios sería entonces sólo de “adaptación”?}

El papel de los medios de comunicación es transformar una controversia científica en controversia social. Y la característica de la controversia social en países democráticos, cuya definición es opinión y soberanía del pueblo, es que el pueblo tiene derecho a opinar. Cuando hay un problema, los medios de comunicación ponen en el espacio público esa controversia, para que el pueblo, según sus características, pueda discutir. Le pongo un ejemplo, el caso actual de la bioética, y antes de la bioética, la interrupción del embarazo, el aborto. En el caso de la bioética, el uso o no de las células madre para resolver problemas de esterilidad y hacer posible el crear, concebir, a pesar de los problemas que puedan tener una mujer o un hombre. La polémica consiste en determinar si las células madre son lo mismo que el embrión. El embrión, para las religiones, en el caso de la religión católica, es un ser humano y no se puede tocar. Los científicos tienen una controversia propia, científica, que consiste en saber si las células madre son lo mismo que el embrión. Pero en el debate público ya son a priori los que llegan, en los que unos dicen: "No, nosotros estamos en contra, porque es matar al ser humano". Para completar la anterior pregunta, todo lo que pasa entonces por el espacio público es para mí "comentario". Cuando la palabra circula en el mundo científico, es "discurso científico"; no es lo mismo que un comentario. Todas las opiniones que se entrecruzan en el espacio público son comentario.

-De acuerdo a sus investigaciones, los procesos de argumentación tienen unos objetivos, entre ellos el explicar una verdad, demostrar una verdad y persuadir a una persona o grupo, y en esto ya entra la política. ¿Se ha acercado usted al discurso del poder en Colombia?

Al discurso del poder en Colombia, no. No lo puedo pretender, porque para hacer análisis del discurso de un país uno tiene que vivir en el país. El discurso no es únicamente lo que se dice, sino todo lo que se implícita, y el que vive en el país país sabe que cuando un político en Colombia habla, detrás de lo que dice hay otra intención, otros sentidos. De modo que yo no me atrevería a hacer comentarios, ni análisis. En cambio, lo que sugiero a mis estudiantes es que 
hagan sus trabajos de manera comparativa, en binomios de países distintos, y que cada uno aporte lo que viene de su propio país, para que después se pueda comparar. Ahora, en cuanto a su pregunta por los procesos de argumentación, puedo decirle de manera general que muchas veces se confunde argumentación y persuasión, y que la argumentación no lo es todo.

Las famosas relaciones de fuerza de las cuales hablaba al principio hacen que cada uno intente influenciar al otro, cambiar la opinión del otro, hacer que el otro comparta nuestra propia opinión. Hay muchos recursos para llegar a eso, incluso el humor, la narrativa, la manera de contar una historia. Hay en verdad muchos recursos y la argumentación es parte de ello. Pero a veces puede ser contraproducente, porque frente a una persona del pueblo, que no tiene muchos estudios y educación, es posible que una argumentación muy rigurosa pueda tener un efecto contrario, porque el otro no la entiende. Incluso quizá la rechazaría diciendo: "Usted es un pedante que me quiere...." Hay otras maneras, otros modos para poder hablar con una persona que no es del mismo nivel cultural que uno e intentar persuadirla, que no es lo mismo que convencerla. Esto no pasa forzosamente por la argumentación. Y el mundo político es propiamente eso. El mundo político no es el mundo científico. El mundo político no es el mundo de la verdad, es el del juego de la verdad: lo que yo llamo el mundo de la veracidad. El mundo de tener razón contra el otro y hacer que la mayoría se adhiera a mi punto de vista, a mi opinión.

-En este juego, por ejemplo, en Colombia nuestros políticos y gobernantes son los mejores del mundo, grandes reformadores que han posicionado a nuestro país como uno de los más equitativos del mundo, destacando por su nivel de justicia social y por ser de las naciones menos corruptas del orbe...

Ese es un gran clásico del discurso político: no hay país en el cual los políticos no digan que el suyo es el más transparente, el menos corrupto, el más justo, el mejor y más próximo al pueblo. Ya no es una característica propia de Colombia, sino la característica de todo hombre político cuando pretende ser elegido. No va a decir "que nuestro país es el peor de todos, el país más corrupto". Al comentar esto usted maneja la ironía, pero la cuestión es saber hasta qué punto este tipo de estrategias utilizadas por los políticos en Colombia tiene impacto, y qué significa en cuanto a lo que es la opinión pública colombiana. En este caso, lo más interesante es cómo los políticos se juegan la adhesión de una mayoría, lo que plantea un problema a la democracia, porque si en realidad se define como la posibilidad 
para el pueblo -por medio de los representantes que se delegan por el poder del voto-, no solamente esos delegados deben tomar en cuenta la mayoría, sino también la minoría.

Como se sabe que el régimen democrático no es perfecto -como decía Winston Churchill: no hay otro mejor-, lo que hace la minoría es organizarse para activar un contrapoder, que puede pasar por asociaciones, por pleitos, por manifestaciones, por protestas, en fin, cantidad de casos, y con cuerpos intermediarios que son los sindicatos, los partidos. Resulta bastante interesante cómo los políticos se las arreglan para determinar qué estrategia usar para llegar a seducir al pueblo y hacer que una mayoría vote por ellos. Implementan una serie de estrategias. Y hay que reconocer que eso va un poco en contra de la argumentación. ¿Cuál es el denominador común que abarca el mayor número de gente, sino es la emoción? Razón por la cual el discurso político usa muchos argumentos emocionales más que argumentos rigurosos, del logos, como se dice, sino más bien del pathos y del ethos, o sea, de la imagen que hacen de ellos mismos y de la manera como llegan a tocar la sensibilidad del pueblo.

\section{- ¿Cuál es, en verdad, el poder de la palabra?¿Qué elementos son indispensables para ejercerlo?}

Es un gran misterio. La palabra no mata, pero puede herir de muerte. En una pareja, por ejemplo, hay cosas que a veces se dicen que no debieron haber sido dichas, que hieren tan fuertemente al otro y pueden tener salidas dramáticas. Pero bueno, una vez se ha dicho eso -que hay palabras que pueden herir fuertemente-, hay que ver después la situación en las cuales se expresan y la identidad de los protagonistas, que sean colectivos o individuales, porque hay situaciones en las cuales incluso un insulto no le importa mucho al otro -se sabe que en el mundo político hay muchos insultos, pero es casi una regla del discurso político-. En cambio, en otras situaciones un insulto puede tener consecuencias dramáticas. No se puede saber, de antemano, el efecto que va a poder tener el uso de una palabra. $\mathrm{Y}$ eso es una cosa importante en el campo educativo, porque los alumnos, los jóvenes no lo perciben, no se dan cuenta que el uso de una palabra puede tener, con respecto al otro, consecuencias fuertes. Uno de los papeles del docente consiste precisamente en hacer que el alumno se dé cuenta de ello: estimular para que adquiera un vocabulario bastante rico como para usar una palabra menos fuerte que la sustituya y tomar conciencia de que ciertas palabras pueden tener efectos desastrosos. 
-Como instrumento mágico, sagrado, la palabra que ofician los sacerdotes y los magos -la palabra en la teúrgia-se contrapone a la palabra "normal", vulgar, incluso, a la palabra que usa el discurso complejo y elaborado.

Es la característica del discurso sagrado. Es discurso sagrado el que se refiere a los textos sagrados. El discurso sagrado no existe en sí, siempre es la referencia a textos que se consideran sagrados, porque son de origen o de inspiración divina, y es uno de los casos en los que no se puede cambiar ni una coma. En todo texto se puede discutir, se pueden cambiar algunas cosas. En un texto sagrado no se puede cambiar nada, porque se supone que es una inspiración del más allá. Entonces, toda palabra que proceda de estos textos se considera palabra sagrada, y la característica de la palabra sagrada es que no se discute, se toma como es, y si se transgrede, ya hay una especie de amenaza, sino del infierno, de una especie de culpa. Actualmente en Francia -no sé si aquí- hay una gran polémica en torno al casamiento que se abre para los homosexuales, y allí se ha visto bien que toda la opinión católica estaba en contra. ¿En contra en nombre de qué? En nombre del matrimonio, que es uno de los sacramentos de la iglesia católica.

Por lo tanto, el matrimonio pasa a ser una especie de palabra sagrada, y el casarse es palabras sagrada para la religión católica. Pero para los laicos, que no se refieren a eso, tiene un valor civil, o sea que en función de una constitución en un país, civilmente, la gente se puede o no se puede casar. Vemos, pues, que las palabras sagradas proceden del mundo religioso donde tienen un valor trascendental. Vemos que también puede haber un fenómeno de valor sagrado de la palabra que pasa en el mundo laico, mundo civil. En Francia, por lo menos, el termino laicidad viene a ser una palabra para todo lo que es en favor de la laicidad. La soberanía popular viene a ser una expresión sagrada en el sistema democrático. Lo sagrado existe en sí, o bien, construido por algo, o por textos sagrados, o porque hay un sistema de tipo ideológico que ha sacralizado esas palabras.

-Usted se refiere al lugar de la palabra en el texto sagrado, pero también hay otra orilla para esta pregunta: la palabra como Fiat lux, como fórmula mágica (el Abracadabra), el conjuro en los grimorios... ¿Qué ocurre con esa palabra sagrada? ¿Cómo la miran los lingüistas? ¿Cómo la concibe usted?

Es algo que no se analiza mucho. Personalmente, no lo he analizado, pero forma parte de lo mismo que he dicho anteriormente. Si, por ejemplo, toda la tradición del vudú, del candomblé, tiene palabras 
con poder mágico en situación y para gente de ese grupo, que se adhiere a eso, el mecanismo al final es el mismo. Ahora, la cuestión del efecto, a eso ya no puedo contestar. Tengo un amigo dominicano que vive en Cuba y se ha iniciado en la Santería. Me dice que cuando "usa palabras" en él, internamente, tienen un efecto fuerte. Muy bien. Yo lo respeto, lo escucho y supongo que es verdad.

-Conocimiento y lenguaje tienen unas relaciones muy entrañables. Pensemos, por ejemplo, en el lenguaje del paraíso, ese jardín que ya perdimos. Umberto Eco, en La búsqueda de la lengua perfecta (1993) hace un rastreo de los lenguajes y la relación con este lenguaje primordial. En El Golem (1915), de Gustav Meyrink, novela a la que Borges dedica un poema, se intenta, con la concepción de una creatura, el ensayo de la lengua divina, para ejercer su poder inherente. ¿Puede recuperarse, mediante el lenguaje humano, un estado genesiaco?

Ese es el gran sueño de los seres humanos: poder llegar a un origen paradisiaco, una Edad de Oro o Edad dorada. Decirlo es tomar conciencia de su finitud, de que los seres humanos vamos a desaparecer y estamos en una búsqueda constante de algo trascendental que nos pudiera dar la ilusión de que sobreviviremos y que llegaremos a romper con ese sentido de la finitud. Todos los grandes relatos, todos los grandes mitos, todas las grandes leyendas están hechas, producidas, por los propios hombres; están construidas precisamente para mantener ese sueño de que algún día podremos vencer la finitud. Y los sueños, sueños son, pero el hombre vive gracias a ellos.

- ¿Qué valor tiene la memoria en el uso de la palabra? Para algunos retóricos clásicos y renacentistas, como Tulio y Bruno, la memoria contaba con un lugar privilegiado: era el "edificio" para almacenar y luego rastrear la palabra. El conocimiento almacenado allí podía ser utilizado en los discursos. Más tarde, cuando la retórica clásica cae en el desprestigio, la memoria también se devalúa con ella.

La teoría de la intertextualidad, de la interdiscursividad, la teoría bajtiniana también lo ha dicho: cada uno de nosotros almacenamos en la memoria, precisamente, saberes compartidos, saberes ya constituidos, y en el momento de hablar nos referimos implícita o explícitamente a ellos: los vamos recuperando. Hay, sin embargo, un juego bastante sutil entre la memoria individual y la memoria colectiva. El mundo político, por su parte, intenta mantener y a veces reactivar una memoria pasada, dependiendo de sus necesidades. 
Por ejemplo, con los países europeos, la característica de la memoria referente a la época de las colonizaciones hace que ahora se discuta si uno debe pedir perdón por todo lo que se hizo durante la colonización o no. Es este un juego de memoria, que no es lo mismo que la historia. Pasa por relatos, por discursos que se dicen, que se mantienen, que desaparecen y vuelven a aparecer. La memoria, en este caso, no corresponde al que "más sabe', sino a lo que circula en una sociedad: los imaginarios colectivos que le sirven para identificarse.

-El lenguaje en la poesía, la poesía en el lenguaje. ¿Cuál es la condición del lenguaje poético que le permite el manejo del vaticinio, de otras dimensiones de la información y del conocimiento?

Puedo decir que la poesía tiene algo en común con el humor, pero también se diferencia de éste. Lo que tiene en común con el humor es la transgresión de las normas lingüísticas. En el caso del humor, para crear un mundo lúdico y establecer una connivencia, una complicidad con el otro; y en el caso de la poesía, para intentar llegar a una visión del mundo -tiene algo "sagrado" también la poesía-, una visión oculta, una visión del mundo que no se conoce, que estaría por detrás de lo normal y cotidiano. El humor, sin embargo, es más frívolo en este aspecto; la poesía es algo más serio, en el sentido de que toca algo de la identidad y la existencia del hombre. Siempre está investigando y hurgando lo que fundamenta la vida. Ese momento un poco sagrado: romper con las apariencias del mundo, como en el mito de la Caverna de Platón, ir y tocar algo escondido que sería algo más significativo: la identidad del hombre. La escritura y la actividad lingüística de la poesía no todos la pueden expresar, es cierto, pero muchos la pueden leer.

\section{-A propósito de uno de los puntos anteriores, podemos ver en sus investigaciones una constante preocupación por el la emoción y el humor.}

Están presentes constantemente, pero no los pongo en el mismo nivel. La emoción es un fenómeno de tipo psicológico que puede pasar por el lenguaje, y no solamente por el lenguaje. El humor es cosa del lenguaje, y aunque también se expresa por un comportamiento físico, es cosa de lenguaje. El punto común entre los dos es que los discursos que manejan la emoción y el humor tienen como fin el influenciar al otro, más por la vía de la seducción que de la persuasión. Si la persuasión corresponde al orden de la razón, el humor y la emoción lo hacen al orden de la pasión. Y los seres humanos somos seres de pasión antes que ser seres de razón. 
-Usted ha publicado algunos libros como Discurso en los medios, Discurso político, Lenguaje y discurso. ¿Ha pensado en replantear o agregar algo sobre ellos? ¿En qué proyecto de escritura se encuentra actualmente?

Nunca se termina de analizar tanto el discurso de los medios como el discurso político. Recientemente acabo de escribir un libro que se titula Conquista del poder, a partir de las últimas elecciones que hubo en Francia, y yo mismo, que había escrito sobre el discurso político, he visto cosas nuevas. Esto es un trabajo sin fin. Ahora, lo más interesante sería poder hacer comparaciones. Por ejemplo, el discurso político en los regímenes democráticos, que no todos se parecen, y cuyo único punto común sería que los representantes del país son todos elegidos. Precisamente por eso deben compararse las estrategias discursivas implementadas en cada país. Analizar tales estrategias revelaría al mismo tiempo lo que es la cultura de un país, la manera como uno se dirige al pueblo, las marcas emocionales que puede usar, cómo piensa un pueblo y su imaginario colectivo. Para mí ahora, lo más interesante es poder comparar los discursos políticos en países distintos. Y lo mismo para los medios de comunicación.

Cartagena, 2013. 
